\title{
Influence of Stock Index Futures on Stock Market Price: Theoretical Analysis and Experiences of the Chinese and Overseas Markets
}

\author{
Huiguan DING \\ College of Economics \& Management, Nanjing Institute of Industry Technology \\ PO box 210046, No.1 Yangshan North Road, Nanjing China \\ Tel: 86-25-8586-4220 E-mail: dinghg1972@163.com \\ Shihong ZENG \\ School of business, Hunan University of Science and Technology \\ PO box 411201, No.1 Taoyuan Road, Xiangtan China \\ Tel: 86-731-5829-0185Ｅ-mail: sdzshh@163.com \\ Xiaojing GUO \\ College of Economics \& Management, Nanjing Institute of Industry Technology \\ PO box 210046, No.1 Yangshan North Road, Nanjing China \\ Tel: 86-25-8586-4221Ｅ-mail: guoxiaojing426@126.com
}

Received: January 19, 2011

Accepted: February 10, 2011

doi:10.5539/ijef.v3n4p113

\begin{abstract}
On April $16^{\text {th }}$ 2010, Shanghai-Shenzhen 300 index futures was put forward, and China's securities market enters into an era of short-position trading. It is an important basic system construction in the capital market, which will have a great impact on the investment concepts, investment structure, investment behaviors and investment strategies of the investors in stock market. This paper makes theoretical analysis on the influences of the launch of stock index futures on stock market price, and takes empirical test of the experiences in the Chinese and overseas markets.
\end{abstract}

Keywords: Stock index futures, Stock price, Influence, Theoretical analysis, Empirical test

\section{Introduction}

On April $16^{\text {th }}$, 2010, Shanghai-Shenzhen 300 index futures contracts are officially listed for trading in China financial futures exchange (CFFEX), which marks the coming of stock index futures era for China's securities market. The launching of Stock-index futures is an important basic system construction in China's capital market with epoch-making significance and opens a new era in the history of the market. The business of stock index futures brings a short-position trading mechanism to the securities market, and China's A-share market ends the 20 -year history of unilateral long-position trading. It is of vital significance to perfecting market function, improving the market structure and optimizing the inner stabilizing mechanism and risk hedge mechanism of the capital market. Stock index futures provides an effective risk management tool for the stock market, thus in the long run is propitious to expand the market's scale, enhance market liquidity, exert the functions of market price discovery and resource allocation. As a systemic reform, stock index futures has a comprehensive influence on the stock market price, mainly in aspects of market capital flows, liquidity, volatility, maturity effect, price structure and running trends etc. This paper makes theoretical analysis on the influence of stock index futures on the stock market price, and takes empirical test of the data in the Chinese and overseas markets.

\section{Stock index futures and liquidity and fluctuation of the stock market}

\subsection{Theoretical analysis of influence of stock index futures on the stock market liquidity and the empirical data}

After Stock index futures are launched, the capital flows in the stock market will change, and the change of the capital chain will directly affect the short-term and long-term running trends of the market price. Stock index futures have a dual effect of short-term capital outflow and long-term capital inflow on the market capitals. Stock index futures has features such as low transaction cost, high leverage multiple and flexible operation, After presentation, it will in the short term attract part of high-risk preferred speculators into the futures market, and a trading shift phenomenon appears, and part of capital flows are drawn to the futures market from stock market, thus temporarily reduce the liquidity in the stock market. That is, stock index futures have a certain "extrusion effect" on the stock 
market funds, but the effect is very limited. On the other hand, in the long run, the introduction of stock index futures has an effect of attracting incremental capitals from outside into stock market. The reason is that stock index futures can dramatically reduce systemic risks in stock market, and the market acquires a hedge tool to prevent risks, and investors have an effective means to make risk management, which helps to attract large long-term funds into the market continuously from numbers of low-risk preferred investors. At the same time, risk-aversion investors increase investment in stock market, and demands for futures-stock arbitrage increase investors' demands for stock trading, and a large number of investors enter into the stock index futures market to make hedge, all of which will make active the tradings in stock market and thus increase the total capital volume and liquidity of the stock market effectively.

Kuserk, Cocke and other researchers (1994) made empirical studies in the stock market of the United States, and the result indicates that after stock index futures trading is introduced, tradings in both stock and futures markets have increased greatly due to numbers of arbitrage traders and hedgers attracted in, which takes on a situation of two-way promotion. In the Japanese market, there appears an obvious phenomenon of trading shift in initial stages after stock index futures is launched, but no remarkable changes in the long term. Researches in markets of Korea, India and China's Taiwan region indicates that the introduction of the stock index futures market increases trading volumes in stock market, but the growth rate of trading volume does not change notably in whether short term or long term before and after stock index futures contracts are listed. (Fang Zhenmin \& Xu Lili, 2007, p.2) Data in overseas markets show that the launch of stock index futures will boost the scales of stock market. In the United States, Japan and Hong Kong, turnovers in stock market increased by $22 \%, 14 \%$ and $50 \%$ respectively in the year when stock index futures is launched, In $2002 \sim 2006$ in global main markets, the compound growth rate of turnovers of stock index futures trading is $30 \%$, while the rate of stock trading is 16\%. (Zhang Xiaofeng, 2010, p.5)

As far as the Chinese market is concerned, the extrusion effect on funds in stock market is not so obvious in the short term, because the entry capital required into the index futures market is relatively high, ordinary investors are hard to enter the market, while institutional investors do not have strong wishes to enter it at early days either. On April $16^{\text {th }}, 2010$ when the index futures are officially launched, the turnover of Shanghai and Shenzhen markets is 190.3 billion Yuan in total. Subsequently, the stock indexes of the two markets keep tumbling, and the volumes shrink with the indexes. On July $2^{\text {nd }}$, the indexes fall to a low point, and the turnover decreases to 119.5 billion. After this, the stock indexes rebound and go higher while the trading volume also increase, and the turnover reaches 488.6 billion on October $18^{\text {th }}$ which is close to the highest amount of history. But in the long run, some institutional investors, such as investment funds, insurance funds, enterprise annuity etc, are with high degree of risk aversion and will gradually enter into the futures market due to needs of hedging. At the same time, overseas funds look good China's long-term economic growth and will put more funds into the market when there exists a hedge tool. Therefore, as far as the overall and long-term development trend of the market is concerned, stock index futures is a fundamental guarantee in expanding the scales of China's stock market and in increasing liquidity of the market, which will eventually be conducive to the long-term, balanced and coordinated development of both the stock market and the futures market of China.

\subsection{Theoretical analysis of influence of stock index futures on price fluctuation of the stock market and the empirical data}

Price fluctuation of the stock market is the external embodiment of market risks. How the launch of stock index futures influences the price fluctuation of the stock market is quite different in different countries and in different stages in the development of the futures market. From the international experiences, the launch of stock index futures may increase the fluctuation of stock prices in short term, but helps stabilise the stock market rather than increase price fluctuation in medium and long term. As a kind of financial derivatives, stock index futures won't change the basic running trend of the stock market, but can reduce large fluctuations in stock market by improving the psychological expectations and investment activities of investors. Stock index futures have basic functions such as risk elusion, hedging and price discovery, so those who enter the market are not only speculators but lots of hedgers. Stock index futures provide a marketized stabilization mechanism for stock market. The usage of its short-position trading mechanism and the exertion of its price discovery function can effectively balance the strength contrast between long position and short position, and restrain sharp rises and falls of the stock market price, therefore help to long-term stability of the market. Meanwhile, stock index futures is a risk management tool, whose long-term price discovery function can guide the rational pricing of the stock market and stabilize market expectations, consequently avoid serious cumulative foam or underestimated value in pricing of stock assets and reduce the market risk of intense turbulence. However, the function can not bring into full play in the short term, there exists a high probability of market deviation and may be a relatively violent vibration in short term, and the linkage actions of the spot and futures markets can also lead to an increasing short-term fluctuations in stock market. 
China's capital market fluctuates hard due to lack of hedge mechanism for a long time, and there is an evident phenomenon of unilateral market in it. Up to 2005, China's stock market has passed through a bear market for more than four years, and the Shanghai composite index reaches the lowest point 998 on June $6^{\text {th }}$. Henceforth, the index keeps rising and hits a history high point 6124 on October $16^{\text {th }}, 2007$ with a rise by $513 \%$ in just 2 years and 4 months, which takes the place of a global crown of champion. After this, China's A-share market falls fast all the way down for the influence of the financial tsunami caused by "subprime mortgage crisis" in US. On October $28^{\text {th }}$, 2008, the index drops to the lowest point 1665 and falls by $71 \%$ within one year, despite the fact that China is one of the world's fastest growing economies during the period. However in the birthplace of the crisis, US sees a biggest drop only by $42 \%$ or so with Dow Jones index. In 22 countries where stock index futures are launched, the average falling range is $46.9 \%$ in their stock markets. In emerging markets where stock index futures are introduced, stock index has fallen only $47.1 \%$. It is obvious that stock index futures play an important role on long-term stability of the stock market.

\section{Stock index futures and the price structure of the stock market}

\subsection{Theoretical analysis of influence of stock index futures on price premium of component stocks of the underlying index}

The launch of stock index futures has a profound impact on stock market structure. It will increase the polarization of both share price structure and listed company structure of the market, and the role of component stocks of underlying index will be enhanced in the whole market. Capital allocation will incline to the component stocks and produce their price premiums correspondingly. In the early stages before stock index futures is launched, institutional investors will increase their demands on the component stocks in spot market out of the needs of risk prevention, arbitrage operation and asset allocation, which will activate the trading of target stocks, attract retail investors to follow up and thus promote the prices of the component stocks, However, the activity degree of non-component stocks will be lowered to some extent as a whole. After stock index futures is launched, the component stocks are overestimated because of early rising and this will lead to value regression, so their prices are mostly on an adjustment situation in the short term. However, the prices will not be affected by stock index futures but mainly by enterprise performances, macro economy and self-valuation level in the long term. In 2009, the economy of China and the world steps gradually out of the shadow of recession under the influence of stimulus packages adopted by many countries during the period of "subprime mortgage crisis", and the stock market also has an obvious rebound. But the subsequent outbreak of "European sovereignty debt crisis" brings new uncertainties to the world economy, and the global stock markets have shown adjustment in succession. In 2010 after Shanghai-Shenzhen 300 index futures is introduced, China's A-share market appears comparatively greater adjustment as a result of the worsening of the Greek debt crisis. Under such backgrounds, the index drops more sharply compared with underlying indexes in overseas markets after their futures are released.

\subsection{Empirical data on influence of stock index futures on stock price structure}

From experiences in the overseas markets, regardless of mature or emerging, the underlying indexes exist premiums in valuation before stock index futures is launched (about half a year or one year), but decline to some extent when the launch date is drawing near. Damocaran (1990) conducts a research based on samples of 378 component shares and 699 non-component shares from NYSE within 5 years after S\&P500 index is launched in April 1982, and calculates the average yield and variance of the sample stocks respectively. The empirical results show that: in the aspect of average reward, rewards of both the index group and the non-index group are improved significantly after stock index futures is listed, the component shares rise by $88 \%$ in average and the non-component shares only $38 \%$, but the average rewards of the two groups have no remarkable difference before the futures is listed; in the aspect of trading volume, the turnover of component shares within 5 years after S\&P500 index futures is launched increases by $98 \%$ compared with that before the launch, however the figure of non-component shares rises by only $42 \%$. In other countries, numerous analysis results also indicate that the component shares of underlying index have certain premiums before stock index futures is launched. (Fang Zhenmin, Xu Lili, 2007, p.11) In India, within around 4 months before NIFTY index futures is launched, the component shares have a relatively substantial increase, and they still have premiums in 2 years after the futures' presentation. In South Korea, within about one year before KOSPI 200 index futures is launched, the component shares of the underlying index go strong obviously, but most of them appear adjustment in short term after the futures' listing. However, the super-scale shares among the components of the underlying index have no significant gains in short term before or after the index futures is launched. From the experiences in the markets of the United States, South Korea and China's Hong Kong and Taiwan, the short-term performances of the super-scale shares are in consistent with the trends of the whole market by and large. In China, it is not so long before Shanghai-Shenzhen 300 index futures is launched, and within the first 3 months after the launch, there is no obvious difference in gains between the underlying index and the composite 
indexes in Shanghai and Shenzhen, which dues to the fact that it takes a certain time for the influence of stock index futures on price structure of the stock market to be demonstrated. Nevertheless, the Shanghai-Shenzhen 300 index decreases by $0.85 \%$ and the Shanghai composite index falls by $5.1 \%$ within the first 6 months after the futures is presented. The phenomenon of the differentiation of share prices has revealed to some extent.

\section{Theoretical analysis and empirical test of "maturity effect" of Stock index futures}

\subsection{Theoretical analysis of "maturity effect" of stock index futures}

Maturity effect refers to the phenomenon that prices appear abnormal fluctuations and are accompanied by a sharply amplified turnover in the stock market due to the imbalance of buying and selling in trading on the date when the stock index futures contract expires. In mature markets, there often exists a "triple-witch effect", that is, stock market prices may fluctuate abnormally at the time when stock index futures, stock index options and stock options expire simultaneously, Maturity effect is caused jointly by factors such as arbitrageurs' closing transactions, hedgers' roll-over transactions and speculators' manipulation over the settlement price of stock index futures. These transactions are accomplished concentratively on the final settlement date, and thus lead to anomalous changes of prices and turnover in the stock market. When stock index futures is approaching its maturity, futures-stock arbitrages gain profits and need to be settled up, therefore, large numbers of arbitrageurs deal with their stock positions in the same direction at the same time, and hedgers switch their near-month contracts into active farther-month contracts continuously on the expiry date in order to preserve the values of stock positions they hold, and speculators will drive the indexes up on the spot market if they are in long position in the futures market and hold the indexes down when in short position. These participants need to manipulate the stock market to gain profits on the maturity date; which thus leads to an increase in volume and a harder price fluctuation in the stock market at the same time.

\subsection{Empirical data on "maturity effect " of stock index futures}

Maturity effect is a prevailing phenomenon in overseas markets. Whaley and Stoll (1991) find in their study on S\&P500 index futures of CME in the United States that: before June 1987, S\&P500 index futures contracts are settled according to closing price on its maturity of Friday, the trading volume within half an hour before closing quotation is $20.8 \%$ of the average volume of two days on the maturity date, but it's only $8.5 \%$ out of the date; after June 1987, the contracts are settled according to opening price on Friday in its maturity, the turnover within half an hour after opening quotation is $26.3 \%$ of the average trading volume of two days on the maturity date, while it's only $8.5 \%$ on non maturity date. The study proves that the turnover of stock index futures contracts emerges a significant change on the expiry date. The results of the research on Nikkei 225 index futures conducted by Karolyi (1996) show that: the index appears unusually large trading volume on the expiry date but with no remarkable price effect economically. In China, Shanghai-Shenzhen 300 index futures have completed seven contracts: IF1005, IF1006, IF1007, IF1008, IF1009, IF1010, IF1011 till November 20, 2010, and the business transactions realize smooth delivery. There appear no abnormal events with either the expiry prices of the contracts within the last 2 hours or the prices of the index. The futures price moves smoothly and always fluctuates slightly around the final settlement price. The final closing prices of the expired contracts converge with their delivery clearing prices very well. The basis has almost no arbitrage space. All these show that there is no obvious "maturity effect " in the China market. The clearing price of Shanghai-Shenzhen 300 index futures contract is the arithmetic average price of the index within the last 2 hours on delivery day, which is the strictest in the world index futures market. On the one hand, the stipulation increases greatly the actual operation difficulties in speculative forces' attempts to manipulate the stock index. On the other hand, it also reserves enough room for closing transactions and roll-over transactions of hedging and arbitraging positions, which avoids the phenomenon of a massive market price fluctuations caused by a great many of market-price orders in both the stock market and the futures market occurred during the last trading period on the expiry date. It is obvious that a scientific design of the trading system compresses the space of "manipulation" in the market and thus weakens the "maturity effect".

\section{Influence of the launching of Stock index futures on the overall price trend of the stock market}

\subsection{Analysis of short-term running trend of stock market before and after stock index futures is launched}

After stock index futures are launched, the short-term performance of the stock market is a result of the integrated effects of the market conditions. From experiences of overseas markets, stock markets have mostly deduced a running course of "rise first and then fall" within short term before and after its launch, which is caused by normal transactions in the markets. Before stock index futures is listed, institutional investors buy in and hold weighted component shares and thus push the indexes high so as to participate in arbitrage transactions of stock index futures in the future and to adjust investment portfolios and asset allocation according to changes in the market. The main reasons for the short-term fall are the pressures of closing transactions when the long-position arbitrages are 
liquidated, which is represented by the United States, Hong Kong, Singapore and London; or that macro-economic risks make short positions dominate the market, and investors directly make short-position speculations or hedge on stock index futures causing the price of stock markets to fall, represented by China's Taiwan region and South Korea.

China's A-share market has also experienced a "rise-first-and-then-fall" process. The background of the presentation of China's stock index futures is that: in August 2007, the "subprime mortgage crisis" starts to sweep over the world's major financial markets such as the United States, the European Union and Japan; in 2008, the crisis is aggravated and spreads worldwide, and many countries introduce the economic stimulus packages in succession; in 2009, the world economy resuscitates gradually, and the stock markets also enter into a phase of rebounding upward; in January 2010, China announces to launch stock index futures business. Therefore, China's stock market is on the rise before the futures is launched. Shanghai composite index rises by $23.5 \%$ within one year, $3.7 \%$ within 2 months and $4.6 \%$ within 1 month before it is introduced. But after its launch, China's stock market falls deep rapidly due to the worsening of the European sovereign debt crisis. The index falls by $18.2 \%$ within 1 month and $22.6 \%$ within 3 months. After 3 months, global stock markets begin to rebound for the reason that EU adopts measures to provide aids over the Greek crisis. As a result, A-share market has also entered into a stage of rise. Although China's stock market falls under an important influence of the world economy, its running trend may also reflect the influence of stock index futures to some degree.

\subsection{Influence on medium- and long-term running trends of stock market after stock index futures is introduced}

The medium- and long-term trends of stock market are determined jointly by the macro-economy and basic status of listed companies. From views of medium- and long-terms, the launch of stock index futures has a neutral effect on the stock market, and the futures does not affect the operation laws of the market, nor change its running trends within the period. Theoretically, the underlying factors that determine the long- and medium-term trends of the capital market are the running status of the macro economy, fundamentals of the listed companies and the valuation level of the market. The macro economy determines the trends of the stock index and the index futures. However, stock index futures, as a trading tool and a risk-management means, is only a derivative product that attaches itself to the spot market and cannot change the fundamentals of the economy or the market's valuation level, and therefore it won't change the long- and medium-term trends of the stock market. The experiences in overseas markets show that the listing of stock index futures won't end a bull market or bear market, and that the stock market keeps rising unchanged if stock index futures is presented in a bullish market, and that it is hard to change the declining trend while the futures is launched in a bearish market. Stock markets in Europe, America and Hong Kong continue going up after stock index futures is launched. In Japan, the market keeps on rising within one year or so after the futures is introduced, but it shifts to a long-term bear market with the overturn of its bubble economy. While the stock markets of South Korea and China's Taiwan region start to decline no sooner than the futures are presented owing to the influence of Southeast Asian financial crisis. Therefore, the most suitable condition for the presentation of stock index futures is that the market is on equilibrium between the bilateral forces of long and short positions, which is in favor of the long-term prosperity and stability of the stock index futures market. Shanghai-Shenzhen 300 index futures are launched in such an equilibrium condition. The influence of the "subprime mortgage crisis" is diminishing gradually. The world economy takes on a tendency to recovery. Market risks are effectively released during the crisis, and the long position and the short position in the market tend to be on equilibrium. Similarly, the determinant factors of the long- and medium- term running trends of China's A-share market are economic growths, changes of macro-economic policy, levels of foreign exchange rate and interest rate, profit growth rates of listed companies and expectations of these factors. Stock index futures will not change the long-and-medium-term trend of A-share market.

\section{References}

Fang, Zhen min, Xu, Lili. (2007). Analysis of Market Influence and Investment Strategy of Stock Index Futures:. Bohai Securities, 1-39.

Rresearch and Development Center.of Hengtai Securities. (2010). Influence of the Launch of Margin Trading and Stock Index Futures on A-share Market and Investment Strategies. Hengtai Securities, 1-7.

Yuan, Kun. (2010). Effect of the Launch of Stock Index Futures on Running Trend of the Stock Market. Journal of China Finance. 034, 80-82.

Xu, Ling. (2010). Stock Index Futures: Trading Purposes, Trading Behaviours and the Particularity of the Development in China. Futures Daily (Zhengzhou), .2 March 2010.

Ding, Nan. (2009). Analysis on Rationality and Difference of China's Futures Market. Journal of Beijing Technology and Business University (social science edition), 24, 38-43. 
Zhu, Yuchen. (2010). Basic Course of Stock Index Futures. Shanghai: Shanghai Far East Press. (Chapter 6).

Zhang, Xiaofeng. (2010). Stock index futures and Margin Trading Open a new era fir A-share market Securities Daily. 9 January 2010.

Table 1. comparison of yield of underlying indexes before and after stock index futures is launched in different countries or regions

\begin{tabular}{|c|c|c|c|c|c|c|c|}
\hline & \multirow{2}{*}{$\begin{array}{c}\text { Launch date of } \\
\text { stock index } \\
\text { futures }\end{array}$} & \multicolumn{2}{|c|}{$\begin{array}{c}\text { Accumulative yield before stock index } \\
\text { futures is launched (\%) }\end{array}$} & \multicolumn{3}{|c|}{$\begin{array}{c}\text { Accumulative yield after stock index } \\
\text { futures is launched (\%) }\end{array}$} \\
\cline { 3 - 8 } & & 3 months & 2 months & 1 month & 1 month & 2 months & 3 months \\
\hline $\begin{array}{c}\text { Standard \& Poor's 500 Index } \\
\text { (US) }\end{array}$ & 1982.4 .21 & -0.27 & 1.96 & 4.37 & -0.98 & -7.29 & -3.61 \\
\hline Nikkei 225 Index (Japan) & 1988.9 .5 & -2.53 & -1.67 & -4.60 & 5.83 & 2.24 & 8.01 \\
\hline $\begin{array}{c}\text { Korean Stock Price Index (S. } \\
\text { Korea) }\end{array}$ & 1996.5 .3 & 9.08 & 12.26 & 8.71 & -7.09 & -13.20 & -14.67 \\
\hline $\begin{array}{c}\text { Hong Kong Heng Seng Index } \\
\text { (China) }\end{array}$ & 1986.5 .6 & 7.14 & 10.42 & 12.08 & -5.90 & -5.46 & 1.66 \\
\hline Taiwan Weighted Index (China) & 1998.7 .21 & -4.65 & -3.84 & 2.95 & -8.53 & -10.06 & -13.84 \\
\hline $\begin{array}{c}\text { Shanghai-Shenzhen 300 Index } \\
\text { (China) }\end{array}$ & 2010.4 .16 & -1.36 & 3.23 & 4.76 & -19.12 & -18.28 & -22.05 \\
\hline $\begin{array}{c}\text { Shanghai Composite Index } \\
\text { (China) }\end{array}$ & - & -2.91 & 3.72 & 4.59 & -18.22 & -18.21 & -22.55 \\
\hline
\end{tabular}

Table 2. Price running trends of the main stock markets in China and overseas before and after stock index futures is launched

\begin{tabular}{|c|c|c|}
\hline $\begin{array}{l}\text { Name of stock index futures } \\
\text { contract }\end{array}$ & Date of launch & $\begin{array}{l}\text { Running trend of the underlying index before and after the presentation of stock index } \\
\text { futures }\end{array}$ \\
\hline S\&P500 index futures (US) & April 21, 1982 & $\begin{array}{l}\text { Presented in a bull market, rise before launch, decline after launch, and on a bullish } \\
\text { market in long and medium term afterwards }\end{array}$ \\
\hline FTSE100 index futures (UK) & May 1984 & $\begin{array}{l}\text { Slight rise before launch, short-term decline after launch, and on a bullish market in } \\
\text { succession for } 17 \text { years afterwards }\end{array}$ \\
\hline $\begin{array}{l}\text { Hong Kong Heng Seng index } \\
\text { futures (China) }\end{array}$ & May 6, 1986 & $\begin{array}{l}\text { Presented in a bull market, break through and reach a new high before launch, adjust for } 2 \\
\text { months after launch, and rebound afterwards }\end{array}$ \\
\hline $\begin{array}{l}\text { Nikkei225 index futures } \\
\text { (Japan) }\end{array}$ & September 3, 1986 & $\begin{array}{l}\text { Presented in the course of a bull market, beneficial to stock market in medium term after } \\
\text { launch, and then promote the falling of the market with the overturn of economic bubble }\end{array}$ \\
\hline CAC40 index futures (France) & Novembe & $\begin{array}{l}\text { Presented during adjustment period after a big bear market, bilateral forces of long and } \\
\text { short positions be locked in a seesaw struggle and then go up }\end{array}$ \\
\hline $\begin{array}{l}\text { DAX30 index futures } \\
\text { (Germany) }\end{array}$ & November 23, 1990 & $\begin{array}{l}\text { Presented in a bull market, go strong within } 1 \text { year before launch, be weak within } 1 \text { year } \\
\text { after launch but do not change a bullish market in the long term }\end{array}$ \\
\hline $\begin{array}{l}\text { KOSPI200 index futures (S. } \\
\text { Korea) }\end{array}$ & May 3, 1996 & $\begin{array}{l}\text { Presented in a bear market, rise before launch and decline after launch, do not change the } \\
\text { long-term trends of stock market }\end{array}$ \\
\hline $\begin{array}{l}\text { Taiwan Composite index } \\
\text { futures (China) }\end{array}$ & July 21, 1998 & $\begin{array}{l}\text { Presented in a bear market after Southeast Asian financial crisis in 1997, rise before } \\
\text { launch, and keep on falling after launch }\end{array}$ \\
\hline SENSEX index futures (India) & Jane 12,2000 & $\begin{array}{l}\text { Presented in a bull market, rise within half a year before launch, decline in short term } \\
\text { after launch, but go up well in long term afterwards }\end{array}$ \\
\hline $\begin{array}{l}\text { Shanghai-Shenzhen } 300 \text { index } \\
\text { futures (China) }\end{array}$ & April 16, 2010 & $\begin{array}{l}\text { Presented after the US subprime mortgage crisis, rise before launch, decline rapidly } \\
\text { because of the worsening of the European sovereign debt crisis after launch, and rebound } \\
3 \text { months afterwards }\end{array}$ \\
\hline
\end{tabular}

